\title{
Prevalence and Intensity of Soil Transmitted Helminths among School Children in Ifetedo, Osun State, Nigeria
}

\section{Oluwarotimi Ademola Omotola* and Ifeanyi Emmanuel Ofoezie}

Institute of Ecology and Environmental Studies, Obafemi Awolowo University Ile-Ife, Osun state, Nigeria

"Corresponding author: Oluwarotimi Ademola Omotola, Institute of Ecology and Environmental Studies, Obafemi Awolowo University Ile-Ife, Osun state, Nigeria, Tel: +234810828 7293; E-mail: rotimiomotola@gmail.com

Received date: August 28, 2018; Accepted date: February 22, 2019; Published date: February 28, 2019

Copyright: $\odot 2019$ Omotola OA, et al. This is an open-access article distributed under the terms of the Creative Commons Attribution License, which permits unrestricted use, distribution, and reproduction in any medium, provided the original author and source are credited.

\begin{abstract}
The study assessed the prevalence, intensity and risk factors affecting the transmission of soil transmitted helminthiasis among school-age children in Ifetedo, Osun State, Nigeria with the view to determining the patterns of transmission of the diseases in the area. The study involved stool examination for infective stages of soil-transmitted helminth parasites using some parasitological analysis. Ascariasis, Trichiuriasis and hookworms infection were the only soil transmitted helminthes (STHs) infections observed among the pupils. The overall prevalence of the diseases was $44.2 \%$ (175 of 396 pupils). The sex related prevalence showed that males (48.6\%) were more infected than females (40.4\%). The peak prevalence (45.9\%) was recorded among the 6-9 years old age group and lowest $(42.4 \%)$ among the youngest children ( $\leq 5$ years old age group). Prevalence and intensity of STHs infection did not vary significantly $(p>0.05)$ among the sexes and age groups. The study concluded that factors such as types of toilets in home and presence of human/animal faeces around home environment are risk factors for STHs infections in the area.
\end{abstract}

Keywords: Geo-helminths; Intensity; Nematodes; Parasites; Prevalence; School-children

\section{Introduction}

The soil-transmitted helminths (STHs) or geo-helminths are nematodes commonly known as intestinal worms. STHs are group of parasitic nematode causing human infection through contact with parasite invasive eggs or larvae. Immature stages (eggs) require incubation in the soil before they become infective. Most often humans become infected by ingestion of infective form of geo-helminths either from soil, raw fruit and vegetables, or dirty hands. They include roundworms (e.g. Ascaris lumbricoides), whipworm (e.g. Trichuris trichiura), threadworm (e.g. Strongyloides stercoralis) and hookworms (e.g. Ancylostoma duodenale and Necator americanus). They are most prevalent in regions exhibiting warm and moist climates coupled with poor sanitation and hygiene. Epidemiologically, it is well established that though individuals of all age's habour worms, the highest rates occur among children in rural areas of the tropical and subtropical areas [1]. Another important risk factor explaining high STHs infection among children is behavioural in nature. Children are generally very active, playing with the soil and objects in the environment with little or no supervision. The preponderance of helminthic infection in school-aged children makes this subgroup a good target for helminth control programmes in the general population and schools provide good opportunities for implementation of control programmes [2].

Human lifestyle and behaviours have been implicated to exacerbate transmission of soil-transmitted helminths. Predominant among these are poverty, inadequate sanitation, lack of access to health care, and overcrowding [3]. Besides, bare footing and eating unwashed fruits and vegetables are also vital risk factors.
Nigeria like other developing countries is faced with the dilemma of inadequate disposal of excreta-related human waste discharged into the environment. Ukpai and Ugwu reported high rate of helminthic infections among people without toilet facilities in Lagos State, Nigeria. In Nigeria, there has been no national school based soil-transmitted helminthes control programme [4]. Also, there are no available data about the demography and hygienic conditions of the children in most schools to help guide the development of school health programmes which are important for sustainable control of soil-transmitted helminths. In the past, there have been sporadic and uncoordinated de-worming programs undertaken by government officials without any baseline information or data [2]. The present study was carried out to determine the prevalence and intensity of soil transmitted infections among school children in the study area.

\section{Materials and Methods}

\section{Study area}

This study was conducted in Ifetedo, Ife South Local Government Area of Osun State in south-western Nigeria. Ifetedo lies between Latitudes $7^{\circ} 1021 \mathrm{~N}$ and $7^{\circ} 1114 \mathrm{~N}$ and Longitudes $004^{\circ} 4125 \mathrm{E}$ and $004^{\circ} 4250 \mathrm{E}$. The inhabitants are predominantly Yoruba speaking people of the Southwest with a mixture of people from different ethnic groups in Nigeria. It is the administrative capital of Ife South Local Government for what reason it has several government offices where the civil servants work. There are six government primary schools in Ifetedo. None of the schools had water supply, few had good toilet facilities. Among the household in Ifetedo, the two major sources of water supply were stream and well. Method of faecal disposal in the primary schools included pit latrine and open defecation. 
Citation: Omotola OA, Ofoezie IE (2019) Prevalence and Intensity of Soil Transmitted Helminths among School Children in Ifetedo, Osun State,

Page 2 of 5

\section{Ethical clearance}

Permission to carry out the investigation was given by the Ife South Local Government Education Board while informed consent of the parents and teachers of the participating pupils was obtained after explaining the objectives of the study at a Parent Teacher Association executives meeting.

\section{Sample collection and administration of questionnaire}

A clean, well labeled plastic bottle was given to each participating pupil for the collection of early morning stool sample. Appropriate instructions on how to collect the stool hygienically was given to the children. The stool samples were retrieved from the pupils the following morning and taken to the laboratory for parasitological examination. In situations where samples could not be examined immediately, $10 \%$ formalin was added to each sample as preservatives.

A structured questionnaire was administered to each participating pupil. The questionnaire was designed to collect information on personal bio-data, characteristics of their homes and the school environment, as well as their perception and knowledge of soil transmitted infections.

\section{Examination of the faecal samples}

The stool samples were examined using modified Kato-Katz method. Each morphologically different egg was counted. The intensity of each helminth observed was determined by multiplying the number of eggs of the species counted by 24 to obtain the number of eggs per gram of faeces (epg).

\section{Data analysis}

Statistical analysis of data was done using both descriptive and inferential methods on the SPSS-23 platform. Descriptive statistics was used to summarize helminth eggs distribution according to age and sex. Chi square $(\chi 2)$ test was used to determine differences in prevalence of STHs infection among levels of different explanatory variables, e.g. gender and age-groups. The Student t-test and one way analysis of variance were used to analyse differences in egg intensity among variables with two levels and more than two levels, respectively. Statistical significance was set at $\mathrm{p}<0.05$.

\section{Results}

Overall 175 of 396 (44.2\%) stool samples examined were positive for soil transmitted helminth eggs. The eggs of soil transmitted helminths observed in the faecal samples were those of Ascaris lumbricoides, Trichuris trichiura and hookworms at prevalence's of $20.7 \%, 12.1 \%$ and $15.7 \%$, respectively (Table 1 ).

\begin{tabular}{|l|l|l|}
\hline \multirow{3}{*}{ Helminths } & $\mathbf{N}=\mathbf{3 9 6}$ & No of positive cases (\%) \\
\hline \multirow{5}{*}{ Double } & Ascaris lumbricoides & $82(20.7)$ \\
\cline { 2 - 3 } & Trichuris trichiura & $48(12.1)$ \\
\cline { 2 - 3 } & Hookworms & $62(15.7)$ \\
\cline { 2 - 3 } & Total & $150(37.9)$ \\
\hline & AL +HW & $10(2.5)$ \\
\cline { 2 - 3 } & AL+TT & $3(0.8)$ \\
\cline { 2 - 3 } & TT+HW & $4(1.0)$ \\
\cline { 2 - 3 } & Total & $17(4.3)$ \\
\hline Overall total Ascaris lumbricoide, TT: Trichuris trichiura, HW: & Hookworm & $175(44.2)$ \\
\hline
\end{tabular}

Table 1: Distribution of STH's infection among the pupils.

Table 2 presents the pattern of infection by age and sex. Out of 183 males examined, $89(48.6 \%)$ were infected while $86(40.5 \%)$ of 213 females examined were infected. Both males and females harboured the three helminth eggs encountered. Prevalence of STH infection was higher in male pupils than females. However, the difference in prevalence was not significant $(\mathrm{p}>0.05)$. There were $39(42.4 \%)$ infections within $\leq 5$ year age category, $72(45.9 \%)$ in 6 to 9 age category and $64(43.5 \%)$ in age $\geq 10$ category as shown in Table 2 below. The difference in prevalence was not significant among age groups.

\begin{tabular}{|l|l|l|l|l|l|}
\hline Parameters & Total examined & No infected & Prevalence & P-value \\
\hline Source of water supply & 278 & 125 & $45.0 \%$ & 0.635 \\
\hline Well & \multicolumn{5}{|l|}{} \\
\hline
\end{tabular}


Citation: Omotola OA, Ofoezie IE (2019) Prevalence and Intensity of Soil Transmitted Helminths among School Children in Ifetedo, Osun State, Nigeria. J Bacteriol Parasitol 10: 352. doi:10.4172/2155-9597.1000352

Page 3 of 5

\begin{tabular}{|c|c|c|c|c|}
\hline Stream & 118 & 50 & $42 . .4 \%$ & \\
\hline \multicolumn{5}{|c|}{ Types of toilet used at home } \\
\hline Pit latrine & 217 & 105 & $48.4 \%$ & 0.001 \\
\hline Water closet & 73 & 15 & $20.5 \%$ & \\
\hline Open defecation & 106 & 55 & $51.9 \%$ & \\
\hline \multicolumn{5}{|c|}{ Parents occupation } \\
\hline Farmer & 140 & 70 & $50 \%$ & 0.203 \\
\hline Artisan & 67 & 31 & $46.3 \%$ & \\
\hline Civil servant & 134 & 50 & $37.3 \%$ & \\
\hline Trader & 55 & 24 & $43.6 \%$ & \\
\hline \multicolumn{5}{|c|}{ Presence of faeces around home environment } \\
\hline Yes & 154 & 82 & $53.2 \%$ & 0.004 \\
\hline No & 242 & 93 & $38.4 \%$ & \\
\hline \multicolumn{5}{|c|}{ Presence of faeces around home and school environment } \\
\hline Yes & 114 & 52 & $45.6 \%$ & 0.717 \\
\hline No & 282 & 123 & $43.6 \%$ & \\
\hline
\end{tabular}

Table 2: Prevalence of soil transmitted helminths in relation to associated risk factors.

The prevalence of STH's in relation to source of water supply was shown in Table 2. Out of 278 children who said their major source of water was shallow well, 125 (45.0\%) were infected, and; 50 out of 118 (42.4\%) who sourced water from streams were infected; prevalence was thus, not significantly different ( $>0.05)$. With respect to access to sanitation facilities, $20.4 \%$ of the pupils that used water closet were infected with at least one helminth species. In contrast, as high as $48.43 \%$ ) of those who used pit latrine and $51.9 \%$ of children who used open defecation were infected, these patterns were significantly different $(\mathrm{p}<0.05)$. Out of 140 children whose parents were farmer, 70 $(50 \%)$ were infected, while $31(46.3 \%)$ of 67 children whose parents were artisans were infected. Among 134 children whose parents were civil servants $50(37.3 \%)$ were infected, as well as $24(43.6 \%)$ of 55 children whose parents were traders. Statistical analysis showed that prevalence did not vary significantly among the various occupational groups ( $\mathrm{p}>0.05)$.

Table 2 shows that out of 154 children living in human/animal faeces infested environment, $82(53.2 \%)$ were infected with at least one helminth disease. Among their counterparts, only 93 (38.4\%) of 242 examined were infected. Statistical analysis showed that prevalence of STH's varied significantly $(\mathrm{p}<0.05)$ according to faecal contamination of the environment. Similarly, 52 (45.6\%) 114 of children exposed to faecally contaminated school environment were infected while only $123(43.6 \%)$ of their 282 counterparts were infected. Unlike the home environment, this trend was not significantly $(\mathrm{p}>0.05)$ different.

Egg count for A. lumbricoides, T. trichiura and hookworm ranged from 48-600, 96-432 and 24-336 per gram of stool (epg), respectively. Mean egg count $( \pm \mathrm{SD})$ for $A$. lumbricoides, T.trichiura and hookworm infections were $67.28 \pm 145.657,34.55 \pm 100.363$ and $24.61 \pm 66.672$, respectively (Table 3 ). The highest mean egg count in males and females $(70.49 \pm 184.01$ and $60.65 \pm 139.34)$ was recorded in the age group 6-9 years for both $A$. lumbricoides and T.trichiura, respectively (Table 3).

\begin{tabular}{|c|c|c|c|c|c|c|c|}
\hline \multicolumn{2}{|c|}{ No examine } & \multicolumn{2}{|l|}{ Hookworms } & \multicolumn{2}{|c|}{ Ascaris lumbricoides } & \multicolumn{2}{|l|}{ Trichuris trichiura } \\
\hline & & No infected (\%) & Mean intensity \pm SD & No infected (\%) & Mean intensity \pm SD & No infected (\%) & Mean intensity \pm SD \\
\hline \multicolumn{8}{|l|}{ Male } \\
\hline$\leq 5$ & 39 & $6(15.4)$ & $20.92 \pm 56.19$ & $12(30.8)$ & $49.23 \pm 89.62$ & $3(7.7)$ & $7.38 \pm 26.49$ \\
\hline $6-9$ & 74 & $16(21.6)$ & $30.10 \pm 68.35$ & $15(20.3)$ & $70.49 \pm 18.00$ & $12(16.2)$ & $60.65 \pm 139.34$ \\
\hline$\geq 10$ & 70 & $11(15.7)$ & $25.71 \pm 70.37$ & $16(22.9)$ & $64.20 \pm 120.83$ & $7(10.0)$ & $27.09 \pm 82.32$ \\
\hline
\end{tabular}


Page 4 of 5

\begin{tabular}{|c|c|c|c|c|c|c|c|}
\hline P-value & & $>0.05$ & $>0.05$ & $>0.05$ & $>0.05$ & $>0.05$ & $>0.05$ \\
\hline Total & 183 & $38(18.0)$ & $26.49 \pm 66.58$ & $43(23.5)$ & $71.64 \pm 145.14$ & $22(12.0)$ & $36.46 \pm 104.66$ \\
\hline \multicolumn{8}{|l|}{ Female } \\
\hline$\leq 5$ & 53 & $8(15.1)$ & $33.51 \pm 86.32$ & $5(9.4)$ & $13.58 \pm 45.75$ & $7(13.2)$ & $15.40 \pm 43.41$ \\
\hline $6-9$ & 83 & $9(10.8)$ & $17.64 \pm 57.59$ & $18(21.7)$ & $97.42 \pm 93.23$ & $9(10.8)$ & $42.22 \pm 122.23$ \\
\hline$\geq 10$ & 77 & $12(15.6)$ & $21.51 \pm 57.16$ & $16(20.8)$ & $61.40 \pm 122.58$ & $10(13.0)$ & $34.91 \pm 91.51$ \\
\hline$P$-value & & $>0.05$ & $>0.05$ & $>0.05$ & $>0.05$ & $>0.05$ & $>0.05$ \\
\hline Total & 213 & $29(13.6)$ & $22.99 \pm 65.74$ & $39(18.3)$ & $63.54 \pm 146.33$ & $26(12.9)$ & $32.9 \pm 96.72$ \\
\hline \multicolumn{8}{|c|}{ All age groups combined } \\
\hline Male & 183 & $33(18.0)$ & $26.49 \pm 66.58$ & $43(23.5)$ & $71.64 \pm 145.14$ & $22(12.0)$ & $36.46 \pm 104.66$ \\
\hline Female & 213 & 29 (13.6) & $22.99 \pm 65.74$ & $39(18.3)$ & $63.54 \pm 146.33$ & $26(12.2)$ & $32.90 \pm 96.72$ \\
\hline $\mathrm{p}$-value & & $>0.05$ & $>0.05$ & $>0.05$ & $>0.05$ & $>0.05$ & $>0.05$ \\
\hline Total & 396 & $62(15.7)$ & $24.61 \pm 66.67$ & $82(20.7)$ & $67.28 \pm 145.65$ & $48(12.1)$ & $34.55 \pm 100.36$ \\
\hline
\end{tabular}

Table 3: Age and sex pattern of mean intensity of STHs infections among the pupils.

There was no significant difference in the mean egg count of $A$. lumbricoides, T. trichiura and hookworm between male and female children (Table 3). Also mean egg counts did not differ significantly among the age groups for both the male and female children.

\section{Discussion}

The occurrences of soil transmitted helminthiasis due to the triad of A. lumbricoides, hookworms and T. trichiura as observed is this study has been reported among children by various authors from different parts of the country [4-7]. The study revealed that, the overall prevalence of the three implicated STHs infection was (44.2\%) in the study area. The findings were comparable with previously reported $46.3 \%$ prevalence based on a study concerning soil-transmitted helminth infections in school children (aged 3-14 years) in Ile-Ife Southwest Nigeria [2]. On contrary, the prevalence in this study was lower compared to some other previous studies done in different regions of Africa. For instance, in a study done in Webuye, Kenya on STHs and intestinal protozoa among children below five years, an overall prevalence of STHs was found to be $52.3 \%$ [8]. Amaeachi et al., also reported a prevalence of helminthiasis among school children in some rural communities of Abia state, Nigeria as $75.7 \%$. Upkai and Ugwu [9] reported 77\% prevalence of intestinal helminthiasis among school children in riverine communities of Nigeria.

The high prevalence rate (44.2\%) of STHs infections among primary school children as obtained could be attributed to carelessness and unhygienic habits practiced by these children both at home and in school. Lack of sanitation facilities in these schools might have also contributed to the high prevalence. In all the selected schools, there were no good toilet facilities. Hence, the children practice open field defecation when in school. The most common combination of soil transmitted helminths in this study is Ascaris and hookworms which agrees with the works of Onuoha et al. [10] and Ali et al. [11] among school children in Enugu and Oyo States respectively but differs from the report of Oyewole et al. who observed high prevalence in coinfection among Ascaris and T. trichiura in Ondo State, Nigeria.

The overall prevalence according to gender among the pupils studied, showed that males $(48.6 \%)$ were more infected than females $(40.4 \%)$ but the difference was not statistically significant. This observation confirms equal exposure to STHs eggs among the study population. However, the higher prevalence of STHs infections in male children was an indication that special activities of males such as playing in contaminated soils could have predisposed them to infections. Sometimes these activities are carried out in the study area while they are bare footed. This was supported by previous studies $[8,12,13]$, who separately reported high prevalence of STHs parasites among males than females due to their activities.

The parental socio-economic status is another important variable determining risk factor predisposing pupils to STHs infection. Occupation was found to be affecting the rate of the infection. The infection was most common among children of farmers. The farmers farm around their houses and keep animals. Most of these animals were not controlled in most cases and as such littered faeces everywhere. Most of the farmers use animal waste as manure, and this can lead to increase soil contamination with STH ova, which in turn lead to increase in the prevalence of infection. This result is in conformity with the report of Kirwan et al. [14] who reported that children of farmers usually harbour higher load of $A$. lumbricoides than those whose parents were businessmen or professionals.

Children who had human/animal faeces around their home environment were more were found to have higher prevalence of STH infections than those who did not have human/animal faeces around their home environment. This was probably due to contamination of soil with faecal material. Similar studies reported such agents being responsible for transmission of helminths parasites [15-18]. The significant association between the presences of human/animal faeces in the vicinity of homes is of great concern and indicates a need for regular environmental sanitation and inspection of in the study area. 
Prevalence of STH infection in relation to source of water in the study area is attributable mostly to streams and rivers which were the main sources of water by the populace. Lack of access to clean water in the study area was a major factor associated with STHs since water is necessary for primary health habit of washing, cleaning, drinking and cooking.

This study shows that the intensity of all positive cases for STHs infection was within the range of light infections and there were no cases with moderate or heavy infection. The intensity of $A$. lumbricoides and T. trichiura follow the same trend, it made a gradual rise from the lowest age group to middle age group (6-9 years old) and then decline among the oldest age group. There was no significant difference between intensity of $A$. lumbricoides among the age groups $(\mathrm{p}>0.05)$

The intensity of hookworm's infection decreases gradually with respect to increase in age of pupils as the highest intensity was recorded among the lowest age group while the lowest intensity was observed among the highest age group. There was no significant difference between intensity of hookworms among the age groups ( $p>0.05$ ). However, the generally low intensities might point to the cultural use of some plants in foods and herbal remedy in the study area. It is possible that the consumption of these local herbal drugs helps to reduce worm burdens. Plants have been shown to have anthelminthic activities $[19,20]$.

This might affect worm survival in the human host and thus reduce faecal egg counts. However, the possible anthelminthic activity of local herbal drugs for worms used in the area needs to be investigated. Low intensity of STH infection observed in this study was in agreement with the findings of [18-20] who separately reported low worm burden.

\section{Conclusion}

The soil-transmitted helminths species causing helminthic infection among children in study area includes $A$. lumbricoides, T. trichiura, and hookworms. The study revealed that $A$. lumbricoides was the most prevalent parasite among the children .The result of this study also showed relatively high prevalence and low intensity of STH infection among the school children.

This study also identified risk factors associated with STHs infections in the study area; factors such as types of toilets in home and presence of human/animal faeces were significantly associated with STHs infections and play a great role in affecting prevalence. There should be means of making the people understand the mode of transmission, and methods of prevention of the infection, alongside chemotherapy approach should be adopted in order to interrupt transmission and to achieve local elimination of helminthiasis and other related intestinal parasites. The farmer should be encouraged to wear boots and hand gloves during farm work and also more hospitals should be built in the study area.

\section{References}

1. Bethony J, Brooker S, Albonico M, Geiger SM, Loukas A (2006) Soil transmitted helminth infections: Ascariasis, trichuriasis and hookworm. Lancet 367: 1521-1532.
2. Ojurongbe O, Oyesiji KF, Ojo JA, Odewale G, Adefioye OA (2014). Soil transmitted helminth infections among primary school children in Ile-Ife, Southwest, Nigeria: A cross sectional study. Int Res J Med Medic Sci 2: 6-10.

3. WHO (2002) Prevention and control of schistosomiasis and soiltransmitted helminthiasis: report of a WHO expert committee. World Health Organization Technical Report Series 912: 1-57.

4. Amaechi E, Ohaeri C, Ukpai OM (2013) Prevalence of helminthiasis among school children in some rural communities of Abia State, Nigeria. Animal Res Int 3: 1817-1825.

5. Asaolu SO, Ofoezie IE (2003) The role of health education and sanitation in the control of helminth infections. Acta Trop 86: 283-294.

6. Ugbomoiko US, Ofoezie IE (2007) Multiple infection diagnosis of intestinal helminthiasis in the assessment of health and environmental effects of development projects in Nigeria. J Helminthol 81: 227-231.

7. Ajayi OO, Odetoyin OO, Awoyeni BW, Adekunle OT (2015) Prevalence of Soil Transmitted Helminthes among School Children in Central Local Government Area Ile-Ife Osun State. Nigeria. Int J Novel Res Interdiscip Stud 2: 8-13.

8. Behnke JM, De Clercq D, Sacko M, Gilbert FS, Ouattara DB (2000) The epidemiology of human hookworm infections in the southern region of Mali. Trop Med Int Health 5: 343-354.

9. Ukpai OM, Ugwu CO (2003) The prevalence of gastro-intestinal tract parasites in the primary school children in Ikuano Local government area of. Abia State, Nigeria. Nig J parasitol 240:129-136.

10. Onuoha EO, Ofoeize IE (2010) Influence of Education Background and Personal Hygiene on Soil Transmitted Helminthiasis in Nsukka Zone, Enugu State, Nigeria in Many Species. One Planet One Future: Proceeding Int Confer Inst Ecol Environ Stud, Obafemi Awolowo Univers Ile-Ife 3: 68-74.

11. Ali I, Mekete G, Wdajo N (2011) Intestinal parasitism and related risk factors among students of Asendabo elementary and junior secondary school, South Western Ethiopia. Ethiop J Health Dev 13: 157-161.

12. Oyewole F, Ariyo F, Oyibo WA, Sanyadu A, Faweya T, et al. (2007) Helminthic reduction with albendazole among children in riverine communities of Nigeria. J Rural Trop Pub Health 6:143-148.

13. Adeyeba OA (2002) Intestinal parasitic infections among school children in a rural community Southwest Nigeria. Nig J Parasitol 23: 11-18.

14. Kirwan P, Asaolu SO, Abiona TC, Jackson AL, Smith HV, et al. (2009) Soil transmitted helminth infections in Nigerian Children aged 0-25 months. J Helminthol 3: 1-6.

15. Bundy DAP, Hall A, Medley GF, Savioli L (2003) Evaluating measures to control intestinal parasitic infections. World Health Statistics 45: 168-179.

16. Blumenthal UJ, Cifuentes E, Bennett S, Quigley M, Ruiz-Palacios G (2011) The risk of enteric infections associated with wastewater reuse: the effect of season and degree of storage of wastewater. Trans R Soc Trop Med Hyg 95:131-137.

17. Adefioye OA, Efunshile AM, Ojurongbe O, Bolaji OS, Adeyeba AO (2011) Intestinal helminthiasis among school children in Ilie, Osun State, Southwest. Nig J Biomed Res 3: 36-42.

18. Ntonifor NG, Irene NS, Tabot JE (2016) Soil-Transmitted Helminth Infections and Associated Risk Factors in a Neglected Region in the Upper Nkongho-mbo Area, South-west Region, Cameroon. Int J Trop Dis Health 16: 1-9.

19. Ojurongbe O, Adegbayi AM, Bolaji OS, Akindele AA, Adefioye OA (2013) Asymptomatic falciparum malaria and intestinal helminths coinfection among school children in Osogbo, Nigeria. J Res Med Sci 16: 680-686.

20. Ross AG, Bartley PB, Sleigh AC, Williams GM, McManus DP (2002) Schistosomiasis. New England J Med 346: 1212-1220. 